\title{
REVIEW
}

\section{Effects of embryonic manipulation and epigenetics}

\author{
Takashi Kohda
}

Embryonic manipulation techniques, such as in vitro fertilization (IVF) and intracytoplasmic sperm injection (ICSI), are widely used in assisted reproductive technology (ART), livestock propagation and application in other fields. Fertilization with IVF and ICSI have been shown to be highly effective, and the mice produced by these techniques develop healthily and with a normal appearance. However, there remains a possibility of epigenetic changes being induced by these techniques. The early stage of mammalian development from fertilization to implantation is a period in which global changes in the epigenetic landscape take place. The sperm and oocyte epigenetic profiles are very different from each other, and the epigenetic remodeling process after fertilization exhibits allelic differences. It is during this period that embryonic manipulation is performed. In this review, I discuss the effects of embryonic manipulation procedures in relation to the epigenetic asymmetry that is present in mammalian early development. Such regulation in the preimplantation embryo provides an important insight into epigenetics. Journal of Human Genetics (2013) 58, 416-420; doi:10.1038/jhg.2013.61; published online 6 June 2013

Keywords: assisted reproductive technology; epigenetic asymmetry; genomic imprinting; intracytoplasmic sperm injection

\section{INTRODUCTION}

Epigenetics was born as a discipline based on the concept of 'epigenesis', which offers a framework for how a variety of cell phenotypes are able to develop from a single identical sequence of genetic code. In particular, the schema of the 'epigenetic landscape' that appeared in Waddington's book, published in $1957,{ }^{1}$ continues to exert an important influence on the field. Since then, the subsequent success and explosive expansion of molecular biology has led to a change in the definition of epigenetics to its current, more modern concept. The most widely accepted definition of epigenetics at present is the one established by Wolffe in $1999,{ }^{2}$ that is, 'epigenetics is the study of heritable changes in gene expression that occur without a change in DNA sequence. However, as the concept of epigenetics has become popularized, this term has grown into an ill-defined, quite ambiguous concept. Here, I wish to propose a new definition, which is 'a cis-acting, gene expression regulation mechanism that is transmitted to the next generation'. This restriction of the concept not only defines the term 'epigenetics' rigorously, but also makes it possible to cogently discuss the future directions of epigenetic research and identification of the as-yet missing pieces in this field in contrast to genetics. For examples, the genetics of multicellular organisms typically deals with the information transmitted from parents to the next generation at the individual level, while 'somatic cell genetics' deals with the information transmitted from the parental cell to daughter cells at the single-cell level in multicellular organisms. In parallel to these two subfields of genetics, we can think about epigenetics operating at two levels as well, that is, epigenetics at the individual and single-cell level, respectively. The former deals with phenomena such as genome imprinting, while the latter deals with matters such as the epi-mutation of tumor suppressor genes in carcinogenesis. $^{3-5}$

In this review, the focus will be placed on the epigenetic regulation that occurs in fertilization and early development. This period is particularly interesting, as the zygote is both a single cell and totipotent, which means that all of the cells in a given organism are derived from this one cell, so the epigenetic changes that take place in the zygote may very well affect all of the cells in the individual. In other words, the epigenetic changes that occur in a germ cell, zygote or preimplantation embryo may define the identity of the individual in a manner similar to the genetic identity that is determined at the time of fertilization. The genetic code is relatively stable, while epigenetic modification may be influenced by external stimulation and/or environmental conditions. As will be discussed later, the epigenetic code in early developmental stage may become altered by environmental stimuli, and this can have an effect on all of the cells in the body. Therefore, the effects of embryonic manipulation and culture techniques on the mammalian embryo, including humans, is a critically important issue in epigenetics.

\section{EFFECTS OF IVF AND EMBRYONIC CULTURE}

The study of mammalian IVF and embryonic culture was begun in the 1950s using experimental animals and livestock to investigate the mechanism of fertilization. In 1978, Edwards succeeded in using IVF to establish a human pregnancy by embryonic transfer. ${ }^{6}$ He was awarded the Nobel Prize in Physiology or Medicine in 2010 for this work. Since then, this technique has been expanded and successfully applied as a basis for ART, and today 1 in 40 children are born by IVF in Japan. From the beginning of the application of ART, there has 
been concern about the influence of the technology on development and many epidemiological studies in relation to this concern have been reported.

There are numerous reports linking ART and certain imprinting diseases, such as Beckwith-Wiedemann syndrome, ${ }^{7-16}$ Angelman syndrome ${ }^{11,17,18}$ and Silver-Russell syndrome ${ }^{19-21}$ (see Table 1). On the other hand, other studies have reported that there is no increased incidence of ART-related imprinting disorders after a proper correction for confounding factors. ${ }^{22}$ It is also reported that the birth weight of children born after the transfer of frozen embryos or a relatively longer in vitro culture was significantly higher when compared with children born without cryopreservation or a shorter in vitro culture. $^{23,24}$ These effects of embryonic culture and cryopreservation are very mild and consistent, with the cause of these phenotypes likely to be an epigenetic or physiological effect. However, it is not easy to identify the cause from among the individual components of the ART used in epidemiologic studies.

On the other hand, it is possible to determine the effects of each individual component of the ART using model animals with defined genotypes under strictly regulated experimental conditions. There have been many reports, for example, that the culture conditions exert an effect on the maintenance of genome imprinting in the mouse ${ }^{25-27}$ (see Table 1).

\section{ICSI EFFECTS}

The ICSI is a technique in which sperm is injected directly into the oocyte using a micromanipulator. This technique was also originally developed to investigate the mechanism of fertilization in animals. In 1992, ICSI was successfully applied to humans by Palermo. ${ }^{28}$ This technique has become increasingly popular as the fertilization method of choice in ART. Today, ICSI is applied to approximately half of the fertilization procedures in Japan. Cohort studies of children conceived by ICSI have reported the risks of genetic and epigenetic impairment.

To elucidate the technical effects of the ICSI procedure itself, we have conducted experiments comparing the regulation of gene expression in certain neonatal tissues, such as the brain, liver and kidney, of mice conceived by either conventional IVF (cIVF) or ICSI using DNA microarrays. ${ }^{29}$ We observed that the gene expression profiles of the ICSI-conceived pups were significantly different compared with the pups conceived by natural mating or cIVF. The gene repertoire affected by ICSI was different in various tissues, and the percentage of genes that exhibited a more than twofold change was in the range of $3-5 \%$ in each tissue. These ICSI effects on gene expression were already observed in the blastocyst stage. Furthermore, the genes affected by ICSI vary depending on the mouse strains from which the sperm was derived. This suggests that the ICSI effect on the epigenetic regulation of the sperm-derived paternal allele occurs at the fertilization step. It was observed that the gene expression changes induced by ICSI were not transmitted to the next generation via sexual reproduction, as far as could be determined. These observations indicate that the ICSI procedure affects the genome at the time of fertilization and induces long-lasting changes in gene expression through the course of development to the neonatal stage. It is also important to assess whether ICSI induces not only transcriptional regulation changes but also phenotypic differences. We thus conducted comprehensive phenotypic analyses comparing IVF and ICSI mice. Consistent with the consensus view, there were no significant phenotypical differences between the ICSI and IVF mice. However, there was a slight reduction of spontaneous activity in the home cage. This difference induced by ICSI was within the range of the characteristics of this strain, however, and all the other data indicated
Table 1 References for epigenetic or epigenetic suspecting disorders in ART

\begin{tabular}{|c|c|c|c|c|c|}
\hline & cIVF & ICSI & $A R T^{\mathrm{a}}$ & $\begin{array}{l}\text { Embryo } \\
\text { culture }\end{array}$ & Cryopreservation \\
\hline \multicolumn{6}{|l|}{ Human disorder } \\
\hline BWS in human & & & $7,8,9,10,11$ & & \\
\hline $\begin{array}{l}\text { No significant or } \\
\text { small difference of } \\
\text { BWS }\end{array}$ & & & 13,22 & & \\
\hline AS in human & & 17,18 & & & \\
\hline SRS in human & 20 & 19 & & & \\
\hline $\begin{array}{l}\text { Birth-weight } \\
\text { increase in human }\end{array}$ & & & & 23,24 & 23,24 \\
\hline $\begin{array}{l}\text { DNA methylation } \\
\text { aberration in } \mathrm{H} 19 \\
\text { DMR }\end{array}$ & 20 & 12,19 & & & \\
\hline $\begin{array}{l}\text { DNA methylation } \\
\text { aberration in } \\
\text { KvDMR }\end{array}$ & & & 14,15 & & \\
\hline $\begin{array}{l}\text { DNA methylation } \\
\text { aberration in } \\
\text { SNRPN DMR }\end{array}$ & & 17 & & & \\
\hline \multicolumn{6}{|l|}{ Mouse model } \\
\hline $\begin{array}{l}\text { Gene expression } \\
\text { changes in mice }\end{array}$ & & $29,30,31$ & & & \\
\hline $\begin{array}{l}\text { DNA methylation } \\
\text { changes in mice }\end{array}$ & & 32 & & $\begin{array}{c}25,26 \\
27\end{array}$ & \\
\hline
\end{tabular}

Abbreviations: AS, Angelman syndrome; ART, assisted reproductive technology; BWS, Beckwith-Wiedemann syndrome; cIVF, conventional IVF; ICSI, intracytoplasmic sperm injection; SRS, Silver-Russell syndrome.

${ }^{a}$ IVF and ICSI.

that there was no difference between ICSI and cIVF. FernándezGonzalez et $a l .{ }^{30}$ reported the long-term consequences of in vitro fertilization on gene expression of the mouse generated by ICSI using frozen-thawed sperm as a model of DNA-damaged sperm. They observed that the ICSI procedure affected both gene transcription and embryonic growth. The causes of the observed effects apparently included both the DNA fragmentation of the sperm and the ICSI procedure itself. Giritharan et al. ${ }^{31}$ also reported gene expression changes at the blastocyst stage induced by ICSI treatment using DNA microarrays. The total number of affected genes was similar to the result in our study, although the repertoire of the affected genes was clearly different, presumably due to differences in the genetic background of the animals used. Recently, a DNA-methylation aberration in the $\mathrm{CpG}$ island of the imprinting control regions also has been reportedly observed in ICSI-conceived mice. ${ }^{32}$

We also reported that the genes that had their expression affected by ICSI showed significant overlap with genes affected by somatic cell cloning by nuclear transfer (SCNT) ${ }^{33}$ Both ICSI and SCNT use the step of nuclear injection with a micromanipulator. Furthermore, it has been reported that the ICSI induces a delay of sperm chromatin decondensation in a strain-dependent manner. ${ }^{34}$ Chromatin decondensation is followed by genome-wide cytosine hydroxymethylation in the male pronucleus, and it is also reported that the hydroxymethylation is affected by the ICSI. ${ }^{35}$ On the other hand, both the paternal and maternal allele of the transplanted nuclei are hydroxymethylated in the case of SCNT. ${ }^{36}$ This evidence suggests that the ICSI and SCNT procedures exert effects on chromatin remodeling and hydroxymethylation in the zygote, and as a result induce epigenetic changes. 


\section{ASYMMETRY OF THE PATERNALLY AND MATERNALLY DERIVED ALLELE}

In somatic cells, it is generally accepted that the paternal and maternal alleles are essentially equivalent. The exception is genome-imprinted genes. They are exclusively expressed from either allele depending on the parent from whom the allele is derived. There are also genes that are expressed mono-allelically, regardless of the parental origin, such as genes subjected to X-chromosome inactivation, immunoglobulin genes, ${ }^{37}$ the T-cell receptor gene and olfactory receptor genes. ${ }^{38}$ It is also reported that there are genes that apparently exhibit random mono-allelic expression; ${ }^{39-43}$ however, both the prevalence of such genes and the precise mechanism of mono-allelic expression remain to be elucidated.

In contrast to somatic cells, paternal and maternal alleles are significantly different in zygote. This is to be expected, as the sperm and oocyte are different types of cells. A recent analysis showed that genome-wide cytosine methylation in the sperm was as high as $90 \%$, whereas that of the oocyte was $\sim 50 \%{ }^{44}$ The sperm nucleus is different from other cells in that the histone proteins are replaced by protamine. After fertilization, protamine is replaced by the histones stored in the oocyte during the decondensation process of the sperm nucleus (Figure 1). However, as a consequence, the histone modification pattern of the paternal pronucleus is substantially different from that of the maternal proncleus. As mentioned above, the genome-wide oxidation of methylcytosine by the Tet enzyme takes place in the paternal pronucleus just after decondensation and chromatin remodeling, while hydroxymethylcytosine is not increased in the maternal pronucleus $^{45,46}$ (Figure 1). This asymmetric conversion of methylcytosine to hydroxymethylcytosine is due to the difference in Dppa3 (Stella/PGC7) binding between the chromatin in the paternal and maternal pronucleus. ${ }^{47,48}$ Shortly after hydroxymethylation, the first DNA replication is initiated ${ }^{49,50}$ (Figure 1). Including this first $S$ phase, the CpG methylation of the maternal allele of the genome is not maintained by the Dnmt1 enzyme, and the so-called passive demethylation does not take place until the morula or blastocyst stage. $^{51}$ As mentioned already, methylcytosine is oxidized to hydroxymethylcytosine in the paternal pronucleus in the zygote. It is reported that the opposite strand of hemi-hydroxymethyl CpG cannot be methylated by Dnmt $1 .^{52}$ Therefore, once methylcytosine is converted to hydroxymethylcytosine, its methylation is not maintained, and thus it is 'passively demethylated. ${ }^{53}$ It is also proposed that the hydroxymethylcytosine may be further converted to cytosine using an excision repair mechanism, ${ }^{54,55}$ but the importance of such an 'active demethylation' pathway still needs to be elucidated. In any event, it is considered that as a result of such paternal and maternal allele asymmetry, the transcriptional activity of each allele is different, even at early embryonic stages. It is not clearly determined whether paternal and maternal pronucleus start zygotic transcription simultaneously; however, the paternal pronucleus is transcriptionally more active than the maternal pronucleus ${ }^{56}$ (Figure 1).

It is not precisely known how long this DNA replication-dependent, passive demethylation continues or when it changes to a maintenance of the methylation status in the course of preimplantation development. However, the methylated regions must be retained in the descendent cell as patches of hemi-methylated regions by a passive demethylation mechanism. When passive demethylation switches to the maintenance of $\mathrm{CpG}$ methylation, then the hemimethylated regions may change to a fully methylated status and become fixed in this state. Assuming this switching takes place at six or seven rounds of cell division, each cell has certain uniquely methylated patches covering $\sim 1 \%$ of the genome. If these patches become a fixed modification, the organism, including a mammalian one, would be a type of chimera in this sense.

The DNA methylation status of each specific gene region is not necessarily the same in the case of genome-wide methylation. For example, the genome-imprinting regulatory region is differentially methylated at fertilization, and this is maintained even after cell division in the course of preimplantation development. This mechanism ensures the genome-imprinting status throughout the organism's lifetime. In order to investigate the epigenetic modification and asymmetry of the paternal and maternal alleles of individual genes other than imprinted genes, a comprehensive allelic expression analysis of the early embryo will be needed. However, considering the epigenetic asymmetry in the period from fertilization to implantation, it is probable that the the paternal and maternal alleles have a

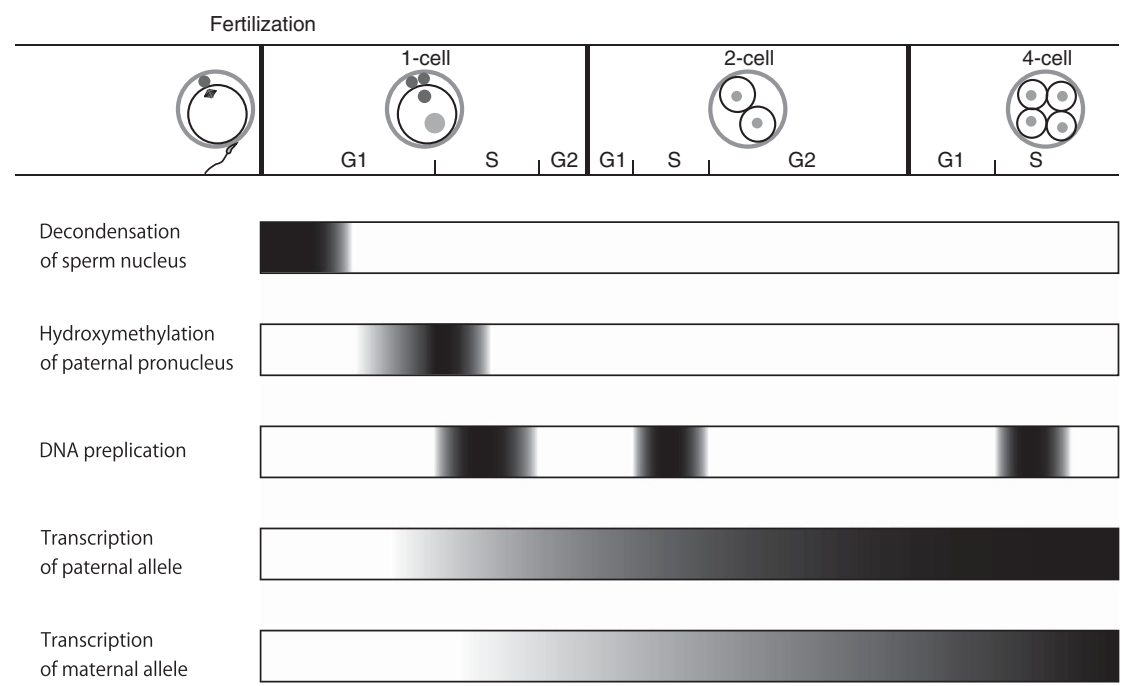

Figure 1 Schematic diagram of epigenetic modification events and gene expression in early mouse development. Drawing that depicts the timing of fertilization, stage of development and the cell cycle (represented as the horizontal axis). Each bar with shade shows a schematic of the timing for the important events for genome-wide epigenetic regulation and the transcription in early development. A full color version of this figure is available at the Journal of Human Genetics journal online. 
different sensitivity to various environmental signals such as the ICSI procedure at the fertilization step, the embryonic culture conditions and so forth. It is also important to elucidate how long the epigenetic changes induced in this period persist and contribute to the epigenetic variation between individuals.

Recently, we set up an experiment to analyze the difference between the paternal and maternal allele by means of transcriptome analysis with RNA-seq using single-nucleotide polymorphisms in a two-cellstage mouse embryo. The preliminary results indicate that ICSI has a differential impact on the mRNA levels of the paternal and maternal alleles ( $\mathrm{T}$ Kohda, unpublished data). This observation suggests that the ICSI procedure at the very least exerts an effect on zygotic gene activation of paternally derived genomes. ${ }^{57}$ Taking an analogy from the field of genetics, this suggests that such a single-allele epigenetic change may be treated as a 'recessive epi-mutation', so the effect does not appear immediately as a phenotype change. However, the risk of the loss of expression of both alleles by a second genetic or epigenetic mutation would likely be increased.

\section{FUTURE PERSPECTIVES}

As the field of epigenetics has grown to be more commonly known, the concept of epigenetics has expanded to the point that it has become vague. As discussed in the introduction, the analogy from genetics provides a useful perspective for the development of epigenetics as a rigorous discipline. Thus, research on the epigenetic changes induced in germ-line cells at the fertilization step and preimplantation development is very important, just like mutations in these periods are important in genetics. It is also critically important to determine the possibility of the transmission of epi-mutation to the next generation in mammals. DNA methylation changes are easily inherited in the next generation in plants. However, the evidence for the inheritance of epigenetic variance is limited in the mammals, such as Agouti ${ }^{\nu y}$ (Morgan et al. ${ }^{58}$ ) and $\mathrm{Axin}(\mathrm{Fu}){ }^{59}$ It is important to know the genes that undergo and the genomic elements that are necessary for epigenetic inheritance.

It is also greatly desired that new technologies be developed for epigenetics that correspond to those used in mammalian genetics, such as transgenic animal models, gene targeting and saturation mutagenesis. For example, a technology that would enable a change to be introduced as an epigenetic modification of any specific locus of the genome will be crucially important for the future development of epigenetics.

\section{ACKNOWLEDGEMENTS}

I gratefully thank Professor Fumitoshi Ishino at Tokyo Medical and Dental University, Dr Atsuo Ogura and Dr Shigeharu Wakana at BioResource Center, RIKEN for precious discussions and collaborative research of the ICSI effects. This work is supported by the Grant-in-Aid for Scientific Research from the Ministry of Education, Science, Sports and Culture of Japan (24310141, 24114505), and Joint Usage/Research Program of Medical Research Institute Tokyo Medical and Dental University.

1 Waddington, C. H. The Strategy of Genes: A Discussion of Some Aspects of Theoretical Biology 262. (George Allen \& Unwin, 1957).

2 Wolffe, A. P. \& Matzke, M. A. Epigenetics: regulation through repression. Science 286, 481-486 (1999).

3 Schofield, P. N., Joyce, J. A., Lam, W. K., Grandjean, V., Ferguson-Smith, A. C., Reik, W. et al. Genomic imprinting and cancer; new paradigms in the genetics of neoplasia. Toxicol. Lett. 120, 151-160 (2001).

4 Suter, C. M., Martin, D. I. K. \& Ward, R. L. Germline epimutation of MLH1 in individuals with multiple cancers. Nat. Genet. 36, 497-501 (2004).
5 Kohda, T., Asai, A., Kuroiwa, Y., Kobayashi, S., Aisaka, K., Nagashima, G. et al. Tumour suppressor activity of human imprinted gene PEG3 in a glioma cell line. Genes to cells 6, 237-247 (2001).

6 Steptoe, P. C. \& Edwards, R. G. Reimplantation of a human embryo with subsequent tubal pregnancy. Lancet 1, 880-882 (1976).

7 DeBaun, M. R., Niemitz, E. L. \& Feinberg, A. P. Association of in vitro fertilization with Beckwith-Wiedemann syndrome and epigenetic alterations of LIT1 and H19. Am. J. Hum. Genet. 72, 156-160 (2003).

8 Gicquel, C., Gaston, V., Mandelbaum, J., Siffroi, J. -P., Flahault, A. \& Le Bouc, Y. In vitro fertilization may increase the risk of Beckwith-Wiedemann syndrome related to the abnormal imprinting of the KCN1OT gene. Am. J. Hum. Genet. 72, 1338-13341 (2003).

9 Maher, E. R., Brueton, L. a., Bowdin, S. C., Luharia, A., Cooper, W., Cole, T. R. et al. Beckwith-Wiedemann syndrome and assisted reproduction technology (ART). J. Med. Genet. 40, 62-64 (2003)

10 Halliday, J., Oke, K., Breheny, S., Algar, E. \& J Amor, D. Beckwith-Wiedemann syndrome and IVF: a case-control study. Am. J. Hum. Genet. 75, 526-528 (2004).

11 Sutcliffe, A. G., Peters, C. J., Bowdin, S., Temple, K., Reardon, W., Wilson, L. et al. Assisted reproductive therapies and imprinting disorders-a preliminary British survey. Hum. Reprod. 21, 1009-1011 (2006).

12 Gomes, M. V., Gomes, C. C., Pinto, W. \& Ramos, E. S. Methylation pattern at the KvDMR in a child with Beckwith-Wiedemann syndrome conceived by ICSI. Am. J. Med. Genet. A. 143, 625-629 (2007).

13 Bowdin, S., Allen, C., Kirby, G., Brueton, L., Afnan, M., Barratt, C. et al. A survey of assisted reproductive technology births and imprinting disorders. Hum. Reprod. 22, 3237-3240 (2007).

14 Gomes, M. V., Huber, J., Ferriani, R. A., Amaral Neto, A. M. \& Ramos, E. S. Abnorma methylation at the KvDMR1 imprinting control region in clinically normal children conceived by assisted reproductive technologies. Mol. Hum. Reprod. 15, 471-477 (2009).

15 Lim, D., Bowdin, S. C., Tee, L., Kirby, G. A., Blair, E., Fryer, A. et al. Clinical and molecular genetic features of Beckwith-Wiedemann syndrome associated with assisted reproductive technologies. Hum. Reprod. 24, 741-747 (2009).

16 Manipalviratn, S., DeCherney, A. \& Segars, J. Imprinting disorders and assisted reproductive technology. Fertil. Steril. 91, 305-315 (2009).

17 Cox, G. F., Bürger, J., Lip, V., Mau, U. a., Sperling, K., Wu, B. -L. et al. Intracytoplasmic sperm injection may increase the risk of imprinting defects. Am. J. Hum. Genet. 71, 162-164 (2002).

18 Ørstavik, K. H., Eiklid, K., Van der Hagen, C. B., Spetalen, S., Kierulf, K., Skjeldal, O. et al. Another case of imprinting defect in a girl with Angelman syndrome who was conceived by intracytoplasmic semen injection. Am. J. Hum. Genet. 72, 218-219 (2003).

19 Bliek, J., Terhal, P., Van den Bogaard, M. -J., Maas, S., Hamel, B., Salieb-Beugelaar, G. et al. Hypomethylation of the $\mathrm{H} 19$ gene causes not only Silver-Russell syndrome (SRS) but also isolated asymmetry or an SRS-like phenotype. Am. J. Hum. Genet. 78, 604-614 (2006).

20 Douzgou, S., Mingarelli, R., Tarani, L, De Crescenzo, A. \& Riccio, A. Silver-Russell syndrome following in vitro fertilization. Pediatr. Dev. Pathol. 11, 329-331 (2008).

21 Kagami, M., Nagai, T., Fukami, M., Yamazawa, K. \& Ogata, T. Silver-Russell syndrome in a girl born after in vitro fertilization: partial hypermethylation at the differentially methylated region of PEG1/MEST. J. Assist. Reprod. Genet. 24, 131-136 (2007).

22 Doornbos, M. E., Maas, S. M., McDonnell, J., Vermeiden, J. P. W. \& Hennekam, R. C. M. Infertility, assisted reproduction technologies and imprinting disturbances: a Dutch study. Hum. Reprod. 22, 2476-2480 (2007).

23 Wikland, M., Hardarson, T., Hillensjö, T., Westin, C., Westlander, G., Wood, M. et al. Obstetric outcomes after transfer of vitrified blastocysts. Hum. Reprod. 25, 1699-1707 (2010)

24 Nakashima, A., Araki, R., Tani, H., Ishihara, O., Kuwahara, A., Irahara, M. et al. Implications of assisted reproductive technologies on term singleton birth weight: an analysis of 25777 children in the national assisted reproduction registry of Japan. Fertil. Steril. 99, 450-455 (2013)

25 Doherty, A. S., Mann, M. R., Tremblay, K. D., Bartolomei, M. S. \& Schultz, R. M. Differential effects of culture on imprinted $\mathrm{H} 19$ expression in the preimplantation mouse embryo. Biol. Reprod. 62, 1526-1535 (2000).

26 Mann, M. R. W., Lee, S. S., Doherty, A. S., Verona, R. I., Nolen, L. D., Schultz, R. M. et al. Selective loss of imprinting in the placenta following preimplantation development in culture. Development 131, 3727-3735 (2004).

27 Market Velker, B. a., Denomme, M. M. \& Mann, M. R. W. Loss of genomic imprinting in mouse embryos with fast rates of preimplantation development in culture. Biol. Reprod. 86, 1-16 (2012).

28 Palermo, G., Joris, H., Devroey, P. \& Van Steirteghem, A. C. Pregnancies after intracytoplasmic injection of single spermatozoon into an oocyte. Lancet 340, 17-18 (1992)

29 Kohda, T., Ogonuki, N., Inoue, K., Furuse, T., Kaneda, H., Suzuki, T. et al. Intracytoplasmic sperm injection induces transcriptome perturbation without any transgenerational effect. Biochem. Biophys. Res. Commun. 410, 282-288 (2011).

30 Fernández-Gonzalez, R., Moreira, P. N., Pérez-Crespo, M., Sánchez-Martín, M., Ramirez, M. A., Pericuesta, E. et al. Long-term effects of mouse intracytoplasmic sperm injection with dna-fragmented sperm on health and behavior of adult offspring. Biol. Reprod. 78, 761-772 (2008).

31 Giritharan, G. Li, M. W. De Sebastiano, F., Esteban, F. J., Horcajadas, J. A., Lloyd, K. C. et al. Effect of ICSI on gene expression and development of mouse preimplantation embryos. Hum. Reprod. 25, 3012-3024 (2010). 
32 De Waal, E., Yamazaki, Y., Ingale, P., Bartolomei, M., Yanagimachi, R. \& McCarrey, J. R. Primary epimutations introduced during intracytoplasmic sperm injection (ICSI) are corrected by germline-specific epigenetic reprogramming. Proc. Natl Acad. Sci. USA 109, 4163-4168 (2012).

33 Kohda, T., Kishigami, S., Kaneko-Ishino, T., Wakayama, T. \& Ishino, F. Gene expression profile normalization in cloned mice by trichostatin a treatment. Cellular Reprogramming 14, 45-55 (2012).

34 Ajduk, A., Yamauchi, Y. \& Ward, M. a. Sperm chromatin remodeling after intracytoplasmic sperm injection differs from that of in vitro fertilization. Biol. Reprod. 75, 442-451 (2006).

35 Yoshizawa, Y., Kato, M., Hirabayashi, M. \& Hochi, S. Impaired active demethylation of the paternal genome in pronuclear-stage rat zygotes produced by in vitro fertilization or intracytoplasmic sperm injection. Mol. Reprod. Dev. 77, 69-75 (2010).

36 Dean, W., Santos, F., Stojkovic, M., Zakhartchenko, V., Walter, J., Wolf, E. et al. Conservation of methylation reprogramming in mammalian development: aberrant reprogramming in cloned embryos. Proc. Natl Acad. Sci. USA 98, 13734-13738 (2001).

37 Pernis, B., Chiappino, G., Kelus, A. S. \& Gell, P. G. Cellular localization of immunoglobulins with different allotypic specificities in rabbit lymphoid tissues. J. Exp. Med. 122, 853-876 (1965).

38 Chess, A., Simon, I., Cedar, H. \& Axel, R. Allelic inactivation regulates olfactory receptor gene expression. Cell 78, 823-834 (1994).

39 Held, W., Roland, J. \& Raulet, D. H. Allelic exclusion of Ly49-family genes encoding class I MHC-specific receptors on NK cells. Nature 376, 355-358 (1995).

40 Holländer, G. A. Monoallelic expression of the interleukin-2 locus. Science 279, 2118-2121 (1998).

41 Rivière, I., Sunshine, M. J. \& Littman, D. R. Regulation of IL-4 expression by activation of individual alleles. Immunity 9, 217-228 (1998).

42 Rhoades, K. L., Singh, N., Simon, I., Glidden, B., Cedar, H. \& Chess, A. Allele-specific expression patterns of interleukin- 2 and $\mathrm{Pax}-5$ revealed by a sensitive single-cell RT-PCR analysis. Current biology: CB 10, 789-792 (2000).

43 Gimelbrant, A. a., Ensminger, A. W., Qi, P., Zucker, J. \& Chess, A. Monoallelic expression and asynchronous replication of p120 catenin in mouse and human cells. J. Biol. Chem. 280, 1354-1359 (2005).

44 Kobayashi, H., Sakurai, T., Imai, M., Takahashi, N., Fukuda, A., Yayoi, O. et al. Contribution of intragenic DNA methylation in mouse gametic DNA methylomes to establish oocyte-specific heritable marks. PLoS. Genet. 8, e1002440 (2012).

45 Iqbal, K., Jin, S. G., Pfeifer, G. P. \& Szabó, P. E. Reprogramming of the paternal genome upon fertilization involves genome-wide oxidation of 5-methylcytosine. Proc. Natl Acad. Sci. USA 108, 3642-3647 (2011).
46 Zhang, P., Su, L., Wang, Z., Zhang, S., Guan, J., Chen, Y. et al. The involvement of 5-hydroxymethylcytosine in active DNA demethylation in mice. Biol. Reprod. 86, 104 (2012).

47 Wossidlo, M., Nakamura, T., Lepikhov, K., Marques, C. J., Zakhartchenko, V., Boiani, M. et al. 5-Hydroxymethylcytosine in the mammalian zygote is linked with epigenetic reprogramming. Nature Communications 2, 241 (2011).

48 Nakamura, T., Liu, Y.-J., Nakashima, H., Umehara, H., Inoue, K., Matoba, S. et al. PGC7 binds histone $\mathrm{H} 3 \mathrm{~K} 9 \mathrm{me} 2$ to protect against conversion of $5 \mathrm{mC}$ to $5 \mathrm{hmC}$ in early embryos. Nature 486, 415-419 (2012).

49 Davis, W., De Sousa, P. A. \& Schultz, R. M. Transient expression of translation initiation factor elF-4C during the 2-cell stage of the preimplantation mouse embryo: identification by mRNA differential display and the role of DNA replication in zygotic gene activation. Dev. Biol. 174, 190-201 (1996).

50 Bui, H. -T. T., Wakayama, S., Mizutani, E., Park, K. -K. K., Kim, J. -H. H., Van Thuan, N. et al. Essential role of paternal chromatin in the regulation of transcriptional activity during mouse preimplantation development. Reproduction 141, 67-77 (2011).

51 Howlett, S. K. \& Reik, W. Methylation levels of maternal and paternal genomes during preimplantation development. Development 113, 119-127 (1991).

52 Hashimoto, H., Liu, Y., Upadhyay, A. K., Chang, Y., Howerton, S. B., Vertino, P. M. et al. Recognition and potential mechanisms for replication and erasure of cytosine hydroxymethylation. Nucleic. Acids. Res. 40, 4841-4849 (2012).

53 Inoue, A., Shen, L., Dai, Q., He, C. \& Zhang, Y. Generation and replication-dependent dilution of $5 \mathrm{fC}$ and $5 \mathrm{caC}$ during mouse preimplantation development. Cell. Res. 21, 1670-1676 (2011)

54 He, Y. -F., Li, B. -Z., Li, Z., Liu, P., Wang, Y., Tang, Q. et al. Tet-mediated formation of 5 -carboxylcytosine and its excision by TDG in mammalian DNA. Science 333, 1303-1307 (2011).

55 Maiti, A. \& Drohat, A. C. Thymine DNA glycosylase can rapidly excise 5-formylcytosine and 5-carboxylcytosine: potential implications for active demethylation of CpG sites. J. Biol. Chem. 286, 35334-35338 (2011).

56 Aoki, F., Worrad, D. M. \& Schultz, R. M. Regulation of transcriptional activity during the first and second cell cycles in the preimplantation mouse embryo. Dev. Biol. 181, 296-307 (1997)

57 Kohda, T. \& Ishino, F. Embryo manipulation via assisted reproductive technology and epigenetic asymmetry in mammalian early development. Philos. Trans. R. Soc. Lond. B. Biol. Sci. 368, 20120353 (2013).

58 Morgan, H. D., Sutherland, H. G., Martin, D. I. \& Whitelaw, E. Epigenetic inheritance at the agouti locus in the mouse. Nat. Genet. 23, 314-318 (1999).

59 Rakyan, V. K., Chong S., Champ, M. E., Cuthbert, P. C., Morgan, H. D., Luu, K. V. K. et al. Transgenerational inheritance of epigenetic states at the murine Axin(Fu) allele occurs after maternal and paternal transmission. Proc. Natl Acad. Sci. U S A 100, 2538-2543 (2003) 